\title{
Protective effect of aqueous extract of Lophira lanceolata leaf against cisplatin- induced hepatorenal injuries and dyslipidemia in Wistar rats
}

\author{
Raphael John Ogbe, Samuel Peter Agbese and Adakole Hyacinth Abu*
}

\begin{abstract}
Background: Hepatorenal injuries and dyslipidemia are common global health challenges but medicinal plant extracts may have potential to prevent them. Thus, this study evaluated the protective effect of aqueous extract of Lophira lanceolata leaf (LLE) against cisplatin-induced hepatorenal injuries and dyslipidemia in albino Wistar rats.

Methods: Thirty rats were randomly divided into 6 groups of 5 rats each. Group I rats received distilled water and served as control, group II rats were given $5 \mathrm{mg} / \mathrm{kg}$ cisplatin (CIS) intraperitoneally, groups III and IV rats were treated with 200 and $400 \mathrm{mg} / \mathrm{kg}$ LLE respectively for 26 days by oral gavages while groups $V$ and VI rats were treated with 200 and 400 mg/kg LLE respectively, followed by CIS on the 21st day as in group II. About $24 \mathrm{~h}$ after treatment, blood was collected from the rats; then serum was separated and used for estimations of biochemical parameters. The kidney and liver of rats were removed, rinsed in normal saline, stored in 10\% formalin and used for histological analyses.

Results: The biomarkers of hepatic (Aminotransferases, Alkaline phosphatase and Bilirubin) and renal (urea and creatinine) injuries, and dyslipidemia (Total cholesterol, triglycerides and LDL-cholesterol) significantly $(p<0.05)$ increased in the rats exclusively exposed to cisplatin when compared with normal control. However, treatment of cisplatin-exposed rats with 200 and $400 \mathrm{mg} / \mathrm{kg}$ LLE significantly $(p<0.05)$ reduced the levels of these biomarkers of hepatorenal injuries and dyslipidemia when compared with cisplatin control. Photomicrographs showed pathological signs in the liver and kidney of rats exclusively exposed to cisplatin, but there was moderate protection of these tissues in the rats treated with LLE and cisplatin.

Conclusion: The current findings have shown that Lophira lanceolata leaf extract may provide moderate protection against cisplatin-induced hepatorenal injuries and dyslipidemia in albino Wistar rats.
\end{abstract}

Keywords: Hepatotoxicity, Histopathology, Hyperlipidemia, Nephrotoxicity

\section{Introduction}

The liver plays a central role in transforming and detoxifying chemicals, so it is susceptible to their toxic effects [1]. Drug-induced liver injury is a cause of acute and chronic liver diseases in animals and humans. Recent epidemiological data suggests that approximately 20 new cases of drug-induced liver injury (DILI) per 100,000 persons occur annually [2]. The Kidney plays a role in

\footnotetext{
* Correspondence: adakoleabu1@gmail.com

Department of Veterinary Physiology and Biochemistry, College of Veterinary Medicine, Federal University of Agriculture, Makurdi P. M. B. 2373, Nigeria
}

homeostasis and excretion of drugs, so it is exposed to drug-induced injuries [3]. The incidence of druginduced kidney injury has increased due to increasing use of drugs, as they are readily available as over-thecounter medicines, especially the non-steroidal antiinflammatory drugs (NSAIDs) and antibiotics [4]. About $20 \%$ of nephrotoxicity is induced by drugs but medication of the elderly increases this incidence up to $60 \%$ as the average lifespan increases [5]. Dyslipidemia is a condition characterized by alteration in the plasma concentrations of lipids (triglycerides and total cholesterols) 
and the blood transporting lipoproteins (LDL-cholesterol, HDL-cholesterol and VLDL-cholesterol). Hyperlipidemia is a common form of dyslipidemia in animals [6].

Cisplatin, chemically known as cis-diamine dichloroplatinum II (CDDP), with chemical formula cis-[Pt $\left.\left(\mathrm{NH}_{3}\right)_{2}(\mathrm{Cl})_{2}\right]$, is a platinum-based chemotherapeutic agent used for treatment of various types of cancers [7]. It is associated with several toxic side effects including nephrotoxicity, hepatotoxicity and oxidative stress injuries. The adverse effects of cisplatin occur by increased production of reactive oxygen species (ROS) and decreased production of antioxidants, though the formation of ROS depends on the concentration and duration of exposure to the drug [8].

Herbal medicine is increasingly getting attention as a useful tool in the management of several disorders. Lophira lanceolata known as "Iron wood" (English) is a tree that grows up to $12 \mathrm{~m}$ high, with a narrow crown, deep root, less scaly bark and contains no latex [9]. It belongs to the Family: Ochnaceae, widely distributed in the West and Central African countries including Nigeria and Cote d'Ivoire [10]. In Nigeria, it is called "Okopia" (Igbo), "Ikponhon" (Yoruba), "Okopi” (Idoma) and "Namijin kadanya" (Hausa) [11]. It is used for the treatment of dermatosis, toothache and muscular tiredness [9]. It is used by many communities in northern Nigeria for the treatment of epilepsy and erectile dysfunction [10]. Previous scientific studies on the leaf extract of this plant revealed antiplasmodial [12] and antibacterial [13] activities. However, there may be paucity of scientific report on the effect of $L$. lanceolata leaf extract on drug-induced hepatorenal disorders and dyslipidemia in animals. Thus, this study was initiated to investigate the protective effect of aqueous extract of $L$. lanceolata leaf against cisplatin-induced hepatorenal injuries and dyslipidemia in albino Wistar rats.

\section{Materials and methods}

Drug used for induction of hepatorenal injuries and dyslipidemia

Cisplatin was the drug of choice for induction of dyslipidemia, liver and kidney injuries in rats. It is an injectable liquid manufactured by Kwality Pharmaceuticals Pvt. Ltd., Nagkalan, Majitha Road, Amritsar, India.

\section{Plant collection and preparation}

The fresh leaves of L. lanceolata were collected from North Bank - Gbajimba road, in Makurdi, Benue State, Nigeria, and identified by a plant taxonomist. The plant leaves were air-dried at room temperature for 2 weeks, pulverized using a grinding machine, and sieved to obtain a fine powder. A $200 \mathrm{~g}$ of pulverized sample was macerated in $4000 \mathrm{ml}$ of distilled water in a conical flask and covered. This was kept at room temperature for 48 $\mathrm{h}$, with frequent agitation after every $2 \mathrm{~h}$. The liquid mixture was filtered with Whatman no.1 filter papers. The filtrate was concentrated and dried by evaporation at $40^{\circ} \mathrm{C}$ using a water-bath. The dried extract was weighed to determine the yield and stored in refrigerator until needed.

\section{Experimental animals and management}

Adult male albino Wistar rats (Rattus norvegicus) weighing 150-230 g, were purchased from the Animal house of College of Health Sciences, Benue State University, Makurdi, Nigeria. The rats were allowed to stabilize and acclimatize for at least 2 weeks before being used for the experiments. They were kept in plastic cages in well ventilated room, fed with standard animal feeds, produced by Grand Cereals and Oil Mills Ltd., Jos, and water ad libitum. The animals were handled with care, according to the principles and standard protocols for the use of laboratory animals for experiments.

\section{Animal grouping and treatments}

The rats were divided into six groups of five animals per group. Group I rats received only distilled water for 26 days by oral gavages and served as normal control. Group II rats were given distilled water for 26 days by oral gavages and administered $5 \mathrm{mg} / \mathrm{kg}$ body weight cisplatin by intraperitoneal (i.p.) route on the 21st day. Groups III and IV rats received 200 and $400 \mathrm{mg} / \mathrm{kg}$ b. wt. Lophira lanceolata extract (LLE) respectively for 26 days by oral gavages. Group V and VI rats received 200 and $400 \mathrm{mg} / \mathrm{kg}$ b. wt. LLE respectively for 26 days while cisplatin was administered on the 21st day as in group II. Body weights of the rats were recorded at the initial week, then second, third and last weeks of the experiment.

\section{Collection and preparation of blood and tissues}

About $24 \mathrm{~h}$ after treatments, rats were sacrificed under chloroform anaesthesia. Blood was collected from rats by intra-cardiac puncture and dispensed into plain sterilized tubes. The blood was allowed to stand on the bench for at least $2 \mathrm{~h}$, spun with a centrifuge at $3000 \mathrm{rpm}$ for $10 \mathrm{~min}$, then serum was separated with clean Pasteur pipette and stored frozen until used for biochemical analyses. The liver and kidney of rats were excised, rinsed in normal saline, weighed and preserved in $10 \%$ formalin for histological analyses.

\section{Biochemical assays}

The biochemical parameters, which are markers of hepatorenal injuries and dyslipidemia, were estimated using assay kits according to the manufacturer's procedures. High density lipoprotein (HDL) cholesterol concentration was determined by the procedure described in the reagent kits instruction manual (AGAPPE Diagnostics 
Ltd., Switzerland). Total cholesterol (TC) and triglyceride (TRG) concentrations were determined by the methods given in the reagent kits instruction manuals (TECO Diagnostics Ltd., USA). Alanine aminotransferase (ALT) and aspartate aminotransferase (AST) activities were determined by IFCC methods, using the kits instruction manual (AGAPPE Diagnostics Ltd). Alkaline phosphatase activity was determined by the method described in the assay kit instruction manual (TECO diagnostics Ltd., USA). Serum bilirubin levels were determined by the modified TAB method described in the assay kits manual (AGAPPE Diagnostic Ltd). The creatinine and total protein concentrations were determined by the methods described in assay kits instruction manuals (Randox Laboratories Ltd., UK). The urea and albumin concentrations were estimated by the methods described in assay kits manuals (AGAPPE Diagnostics Ltd).

The atherogenic/dyslipidemic indices were calculated using the equations, according to previously described methods $[14,15]$.

1. Cardiac risk ratio $(\mathrm{CRR})=$ Total cholesterol $/ \mathrm{HDL}$ cholesterol

2. Atherogenic coefficient $(\mathrm{AC})=$ Total cholesterol HDL cholesterol/HDL cholesterol

3. Atherogenic index of plasma (AIP) $=\log$ (Triglycerides/HDL cholesterol)

4. Classical ratio $(\mathrm{CR})=\mathrm{LDL}$ cholesterol $/ \mathrm{HDL}$ cholesterol

\section{Histological analyses of liver and kidney tissues}

Histopathological examination was carried out according to a previously described method [16]. The liver and kidney tissues were fixed in $10 \%$ formalin, dehydrated, embedded in paraffin, sectioned and stained with hematoxylin and eosin. The stained glass slides were viewed under light microscope at $\times 10$ and 40 objective lenses.

\section{Statistical analysis}

The statistical package for the social sciences (SPSS version 21.0) produced by SPSS Inc., Chicago, USA, was used for statistical analysis. Data were presented as mean \pm standard error of mean (SEM), with $n=5$. The data were analyzed by one-way analysis of variance

(ANOVA), followed by least significant difference (LSD) as Post Hoc test for multiple comparisons. Mean differences were considered statistically significant at $p<0.05$.

\section{Results}

Effect of Lophira lanceolata leaf extract on biomarkers of hepatic injuries in rats

There was a significant $(\mathrm{p}<0.05)$ elevation in the activities of serum alanine aminotransferase (ALT), aspartate aminotransferase (AST), alkaline phosphatase (ALP) and total bilirubin levels of cisplatin-exposed rats when compared with the normal control. There was no significant $(p>0.05)$ difference in the levels of total proteins and albumin of rats in all the treatment groups compared with normal control. However, treatment with aqueous extract of $L$. lanceolata leaf significantly $(p<0.05)$ reduced the levels of ALT, AST and total bilirubin of cisplatinexposed rats when compared with the cisplatin control (Table 1).

\section{Effect of Lophira lanceolata leaf extract on lipid profile and biomarkers of renal injuries in rats}

There was a significant $(p<0.05)$ increase in the levels of T-cholesterol, triglycerides and LDL-cholesterol of cisplatin-exposed rats when compared with the normal control. There was no significant $(p>0.05)$ difference in the levels of HDL-cholesterol of rats in all the treatment groups. However, treatment with 200 and $400 \mathrm{mg} / \mathrm{kg}$ b. wt. aqueous extract of $L$. lanceolata leaf significantly $(p<0.05)$ reduced the levels of T-cholesterol, triglycerides and LDL-cholesterol of cisplatin-exposed rats when compared with the cisplatin control (Table 2). There was a significant $(p<0.05)$ increase in the levels of urea and creatinine of cisplatin-exposed rats when compared with normal control. However, treatment with 200 and $400 \mathrm{mg} / \mathrm{kg}$ b. wt. aqueous extract of $L$. lanceolata leaf significantly $(p<0.05)$ reduced the levels of urea and creatinine of cisplatin-exposed rats when compared with cisplatin control (Table 2).

\section{Effect of Lophira lanceolata leaf extract on percentage organ to body weight ratio of rats}

There was a significant $(p<0.05)$ reduction in the weights of liver, kidney, ratio of liver to body weight and kidney to body weight of cisplatin-exposed rats when compared with normal control. The treatment of cisplatin-exposed rats with 200 and $400 \mathrm{mg} / \mathrm{kg}$ LLE significantly $(p<0.05)$ increased their ratio of liver to body weight and kidney to body weight when compared with cisplatin control. There was also significant $(p<0.05)$ increase in the weights of liver and kidney of cisplatinexposed rats treated with $200 \mathrm{mg} / \mathrm{kg}$ LLE when compared with cisplatin control. However, there was no significant $(p>0.05)$ difference in the weights of liver and kidney of rats given 200 and $400 \mathrm{mg} / \mathrm{kg}$ LLE only when compared with the normal control (Table 3).

\section{Effect of Lophira lanceolata leaf extract on atherogenic/ dyslipidemic indices in rats}

There were increases in cardiac risk ratio (CRR), atherogenic coefficient $(\mathrm{AC})$, classical ratio $(\mathrm{CR})$ and atherogenic index of plasma (AIP) of cisplatin-exposed rats when compared with the normal control. The rats treated with $200 \mathrm{mg} / \mathrm{kg}$ b. wt. showed slight increases in 
Table 1 Effect of Lophira lanceolata leaf extract on biomarkers of hepatic injuries in rats administered cisplatin

\begin{tabular}{|c|c|c|c|c|c|c|}
\hline \multirow[t]{2}{*}{ Treatment groups } & \multicolumn{6}{|c|}{ Serum biomarkers of hepatic injuries } \\
\hline & T-Protein $(\mathrm{g} / \mathrm{dL})$ & Albumin $(\mathrm{g} / \mathrm{dL})$ & $\mathrm{ALT}(\mathrm{U} / \mathrm{L})$ & AST $(U / L)$ & $\mathrm{ALP}(\mathrm{U} / \mathrm{L})$ & T-Bilirubin (mg/dL) \\
\hline I. Normal control & $6.68 \pm 0.69$ & $3.00 \pm 0.13$ & $30.12 \pm 3.46$ & $27.56 \pm 5.17$ & $22.32 \pm 6.59$ & $0.62 \pm 0.12$ \\
\hline II. $5 \mathrm{mg} / \mathrm{kg}$ Cisplatin & $6.42 \pm 0.70$ & $3.50 \pm 0.32$ & $178.0 \pm 38.5^{\mathrm{a}}$ & $73.44 \pm 2.75^{\mathrm{a}}$ & $48.04 \pm 3.09^{\mathrm{a}}$ & $3.78 \pm 1.15^{\mathrm{a}}$ \\
\hline III. 200 mg/kg LLE & $6.48 \pm 0.41$ & $3.12 \pm 0.26$ & $33.72 \pm 5.98^{b}$ & $37.14 \pm 9.58^{b}$ & $35.32 \pm 5.87$ & $0.56 \pm 0.09^{b}$ \\
\hline IV. $400 \mathrm{mg} / \mathrm{kg}$ LLE & $5.56 \pm 0.37$ & $2.98 \pm 0.16$ & $31.50 \pm 2.83^{b}$ & $30.22 \pm 3.26^{b}$ & $39.36 \pm 10.1$ & $0.48 \pm 0.17^{b}$ \\
\hline V. $200 \mathrm{mg} / \mathrm{kg}$ LLE + CIS & $7.28 \pm 0.88$ & $3.12 \pm 0.16$ & $44.08 \pm 8.18^{b}$ & $42.56 \pm 4.49^{b}$ & $34.60 \pm 6.28$ & $0.40 \pm 0.14^{b}$ \\
\hline VI. 400 mg/kg LLE + CIS & $6.24 \pm 0.42$ & $2.90 \pm 0.20$ & $66.40 \pm 6.65^{b}$ & $34.16 \pm 2.82^{b}$ & $34.40 \pm 5.36$ & $1.86 \pm 0.10^{b}$ \\
\hline
\end{tabular}

Values are Mean \pm SEM, $n=5$; LLE - Lophira lanceolata leaf extract, CIS - Cisplatin

a significantly different from normal control $(p<0.05)$

${ }^{\mathrm{b}}$ significantly different from cisplatin control $(p<0.05)$

CRR, AC, and CR while those treated with $400 \mathrm{mg} / \mathrm{kg} \mathrm{b}$. wt. showed slight decreases in CRR, AC and AIP when compared with normal control. However, the treatment of cisplatin-exposed rats with 200 and $400 \mathrm{mg} / \mathrm{kg}$ b. wt. LLE decreased their CRR, AC, CR and AIP when compared with cisplatin control. Though, the decreases in CRR, AC, CR and AIP values were greater by treatment of cisplatinexposed rats with $200 \mathrm{mg} / \mathrm{kg}$ than $400 \mathrm{mg} / \mathrm{kg}$ LLE (Table 4).

\section{Histopathological findings in liver and kidney of rats treated with $L$. lanceolata extract}

The photomicrographs of liver and kidney sections of rat given only distilled water appeared normal, without signs of degenerative changes. The hepatocytes and liver sinusoids appeared normal while the glomerulus, Bowman's capsule and renal tubules also appeared normal (Figs. 1a and $b$ ). The photomicrographs of liver and kidney sections of a rat exposed to $5 \mathrm{mg} / \mathrm{kg}$ b.wt. CIS showed signs of hepatorenal injuries. There was sinusoidal dilatation, vascular congestion, infiltration of portal triad and stroma of liver by inflammatory cells, and foci of coagulative necrosis. The kidney tissues showed capsular dilation, distorted glomeruli, and congestion of interstitial spaces, showing signs of interstitial nephritis (Figs. 2a and b).
The photomicrographs of liver and kidney sections of rat treated with $200 \mathrm{mg} / \mathrm{kg}$ LLE showed mild hepatorenal injuries. There was mild congestion of interstitial spaces and foci of interstitial nephritis. There was infiltration of hepatic cords by few inflammatory cells and foci of mild coagulative necrosis (Figs. 3a and b). The photomicrographs of liver and kidney sections of rat treated with $400 \mathrm{mg} / \mathrm{kg}$ LLE showed mild hepatorenal injuries. There was mild congestion of renal interstitial spaces, and some glomeruli were shrunken with dilated capsular spaces. There was infiltration of portal triad and hepatic cords by inflammatory cells, and mild congestion of liver sinusoids (Figs. 4a and b).

The photomicrographs of liver and kidney sections of rat treated with $200 \mathrm{mg} / \mathrm{kg} \mathrm{LLE}$ and exposed to $5 \mathrm{mg} / \mathrm{kg}$ CIS showed mild hepatorenal injuries. There were few shrunken glomeruli, infiltration of renal tubules by inflammatory cells and congestion of interstitial spaces, showing signs of mild interstitial nephritis. There was congestion of few sinusoids in the liver, which was mild when compared with the CIS control (Figs. 5a and b). The photomicrographs of liver and kidney sections of rat treated with $400 \mathrm{mg} / \mathrm{kg}$ LLE and exposed to $5 \mathrm{mg} / \mathrm{kg}$ CIS showed mild hepatorenal injuries and signs of recovery. There were pockets of hemorrhage seen in the

Table 2 Effect of Lophira lanceolata leaf extract on lipid profile and biomarkers of renal injuries in rats administered cisplatin

\begin{tabular}{|c|c|c|c|c|c|c|}
\hline \multirow[t]{2}{*}{ Treatment groups } & \multicolumn{6}{|c|}{ Serum lipid profile and biomarkers of renal injuries } \\
\hline & Total Chol. (mg/dL) & TRG $(\mathrm{mg} / \mathrm{dL})$ & HDL-Chol. (mg/dL) & LDL-Chol. (mg/dL) & Urea (mg/dL) & Creatinine $(\mathrm{mg} / \mathrm{dL})$ \\
\hline I. Normal control & $116.6 \pm 3.1$ & $129.2 \pm 5.1$ & $36.82 \pm 3.09$ & $46.84 \pm 3.15$ & $27.46 \pm 4.68$ & $0.44 \pm 0.17$ \\
\hline II. 5 mg/kg Cisplatin & $194.8 \pm 24.0^{a}$ & $149.5 \pm 2.9^{a}$ & $36.68 \pm 3.20$ & $133.5 \pm 17.4^{\mathrm{a}}$ & $65.14 \pm 6.96^{a}$ & $1.92 \pm 0.39^{a}$ \\
\hline III. 200 mg/kg LLE & $127.2 \pm 11.9^{b}$ & $117.7 \pm 4.2^{b}$ & $37.00 \pm 3.84$ & $58.78 \pm 8.20^{b}$ & $32.34 \pm 3.71^{b}$ & $1.06 \pm 0.24^{b}$ \\
\hline IV. $400 \mathrm{mg} / \mathrm{kg}$ LLE & $94.2 \pm 8.01^{\mathrm{b}}$ & $136.1 \pm 1.9$ & $40.40 \pm 1.30$ & $56.22 \pm 6.10^{\mathrm{b}}$ & $33.08 \pm 4.33^{b}$ & $0.48 \pm 0.07^{b}$ \\
\hline V. CIS + $200 \mathrm{mg} / \mathrm{kg} \mathrm{LLE}$ & $109.3 \pm 5.12^{b}$ & $146.6 \pm 14.6$ & $41.44 \pm 2.24$ & $31.72 \pm 5.48^{b}$ & $30.28 \pm 1.10^{b}$ & $0.46 \pm 0.09^{b}$ \\
\hline VI. CIS + 400 mg $/ \mathrm{kg}$ LLE & $129.8 \pm 0.82^{b}$ & $128.8 \pm 1.9^{b}$ & $35.54 \pm 4.73$ & $80.92 \pm 5.27^{\mathrm{ab}}$ & $38.08 \pm 5.67^{b}$ & $0.42 \pm 0.19^{b}$ \\
\hline
\end{tabular}

Values are Mean \pm SEM, $n=5$; LLE - Lophira lanceolata leaf extract, CIS - Cisplatin

${ }^{\mathrm{a}}$ significantly different from normal control $(p<0.05)$

${ }^{\mathrm{b}}$ significantly different from cisplatin control $(p<0.05)$ 
Table 3 Effect of Lophira lanceolata leaf extract on percentage of organ to body weight ratio of rats administered cisplatin

\begin{tabular}{llllll}
\hline Treatment groups & \multicolumn{5}{l}{ Body weight and percentage of organ to body weight ratio } \\
\cline { 2 - 6 } & Body weights(g) & Liver weights(g) & Liver/Body weights (\%) & Kidney weights(g) & Kidney/Body weights (\%) \\
\hline I. Normal control & $195.0 \pm 10.37$ & $5.66 \pm 0.28$ & $2.9 \pm 0.20$ & $0.65 \pm 0.05$ & $0.33 \pm 0.01$ \\
II. 5 mg CIS & $233.8 \pm 11.08^{\mathrm{a}}$ & $4.25 \pm 0.08^{\mathrm{a}}$ & $1.8 \pm 0.10^{\mathrm{a}}$ & $0.49 \pm 0.01^{\mathrm{a}}$ & $0.21 \pm 0.009^{\mathrm{a}}$ \\
III. $200 \mathrm{mg} \mathrm{LLE}$ & $195.4 \pm 5.27^{\mathrm{b}}$ & $5.91 \pm 0.09^{\mathrm{b}}$ & $3.02 \pm 0.07^{\mathrm{b}}$ & $0.58 \pm 0.01$ & $0.30 \pm 0.006^{\mathrm{b}}$ \\
IV. $400 \mathrm{mg} \mathrm{LLE}$ & $198.6 \pm 6.21$ & $6.66 \pm 0.27^{\mathrm{b}}$ & $3.35 \pm 0.16^{\mathrm{b}}$ & $0.60 \pm 0.01^{\mathrm{b}}$ & $0.30 \pm 0.008^{\mathrm{b}}$ \\
V. $200 \mathrm{mg} \mathrm{LLE}+$ CIS & $209.0 \pm 7.38$ & $5.59 \pm 0.38^{\mathrm{b}}$ & $2.67 \pm 0.14^{\mathrm{b}}$ & $0.72 \pm 0.01^{\mathrm{b}}$ & $0.34 \pm 0.01^{\mathrm{b}}$ \\
VI. $400 \mathrm{mg} \mathrm{LLE}+$ CIS & $197.4 \pm 3.78^{\mathrm{b}}$ & $5.00 \pm 0.27$ & $2.53 \pm 0.09^{\mathrm{b}}$ & $0.76 \pm 0.01^{\mathrm{ab}}$ & $0.39 \pm 0.02^{\mathrm{b}}$ \\
\hline
\end{tabular}

Values are Means \pm SEM, $n=5$; LLE - Lophira lanceolata leaf extract, CIS - Cisplatin

${ }^{a}$ significantly different from the normal control $(p<0.05)$

${ }^{\mathrm{b}}$ significantly different from the cisplatin control $(p<0.05)$

interstitial spaces and signs of recovery from renal injuries. There was mild hemorrhage and infiltration of portal triad of the liver by inflammatory cells, which was less severe when compared with CIS control (Figs. 6a and b).

\section{Discussion}

The alterations of alanine aminotransferase (ALT) and aspartate aminotransferase (AST) activities are biochemical indicators of hepatocellular injuries [17]. The significant increase in serum AST and ALT activities, after exposure of rats to cisplatin may indicate liver injuries, attributed to the adverse effect of this drug. Previous studies have shown that increases in serum AST and ALT activities reflect hepatocellular membrane damage and leakage $[2,17]$. The significant increase in alkaline phosphatase (ALP) activity may also indicate liver impairments and cholestasis, due to the adverse effect of cisplatin. ALP activity increases as a result of biliary obstructions or cholestasis, thus it is a biomarker of hepatobiliary disease [2].

The alteration in serum bilirubin levels is a biochemical indicator of the changes in morphological integrity of hepatobiliary tract, as a sign of liver damage [17-19]. Elevated levels of bilirubins may be due to excessive haemolysis or biliary tract obstruction [18]. The significant increase in serum total bilirubin may indicate impaired hepatic excretory function, a sign of liver dysfunction, attributed to the adverse effect of cisplatin. These findings are in agreement with El-Hosseiny et al. [2] who found significant elevation in the levels of total bilirubin, after exposure of rats to a drug. Bilirubin is the excretory product formed by catabolism of heme in hemoglobin, thus hyperbilirubinemia is usually caused by excessive destruction of heme and blockage of biliary tract; which results in severe inhibition of conjugation reaction and release of unconjugated bilirubin from damaged and dead hepatocytes [18]. The significant reduction of AST, ALT, ALP and bilirubin levels after treatment of cisplatin-exposed rats with LLE may indicate a protective effect of this plant extract against cisplatin-induced hepatic injuries. The LLE may have stabilized hepatocyte membrane integrity against cisplatin lethality, thereby preventing elevation of these biomarkers of hepatic injuries in rats. Some plant extracts have earlier been reported to produce protective effects against drug-induced liver injuries in animals by reduction of ALT, AST, ALP and bilirubin levels $[2,19]$.

Creatinine and urea levels are used as biochemical markers of kidney injuries, thus elevated levels of these markers may indicate kidney dysfunction, though the test for creatinine is a better indicator than urea [20]. Creatinine is a non-protein nitrogenous substance

Table 4 Effect of Lophira lanceolata leaf extract on atherogenic/dyslipidemic indices in rats administered cisplatin

\begin{tabular}{|c|c|c|c|c|}
\hline \multirow[t]{2}{*}{ Treatment groups } & \multicolumn{4}{|c|}{ Atherogenic/dyslipidemic indices of rats } \\
\hline & Cardiac risk ratio (CRR) & Atherogenic coefficient (AC) & Atherogenic index (AIP) & Classical ratio $(C R)$ \\
\hline Normal control & 3.17 & 2.17 & 0.55 & 1.27 \\
\hline Cisplatin control & $5.31(67)^{\mathrm{a}}$ & $4.31(98)^{a}$ & $0.61(11)^{a}$ & $3.64(186)^{a}$ \\
\hline 200 mg/kg LLE only & $3.44(9)^{\mathrm{a}}$ & $2.44(12)^{a}$ & $0.50(9)^{\mathrm{a}}$ & $1.59(25)^{\mathrm{a}}$ \\
\hline 400 mg/kg LLE only & $2.33(27)^{a}$ & $1.33(39)^{\mathrm{a}}$ & $0.53(4)^{a}$ & $1.39(9)^{a}$ \\
\hline $200 \mathrm{mg} / \mathrm{kg}$ LLE + ClS & $2.64(50)^{b}$ & $1.64(62)^{b}$ & $0.55(10)^{b}$ & $0.76(79)^{b}$ \\
\hline $400 \mathrm{mg} / \mathrm{kg}$ LLE + CIS & $3.65(31)^{b}$ & $2.65(39)^{\mathrm{b}}$ & $0.56(8)^{\mathrm{b}}$ & $2.27(38)^{b}$ \\
\hline
\end{tabular}

Values are means of 5 rats; Values in parenthesis are percentage changes (\%), CIS - Cisplatin, LLE - Lophira lanceolata leaf extract a percentage changes when compared with normal control

bercentage decrease when compared with cisplatin control 


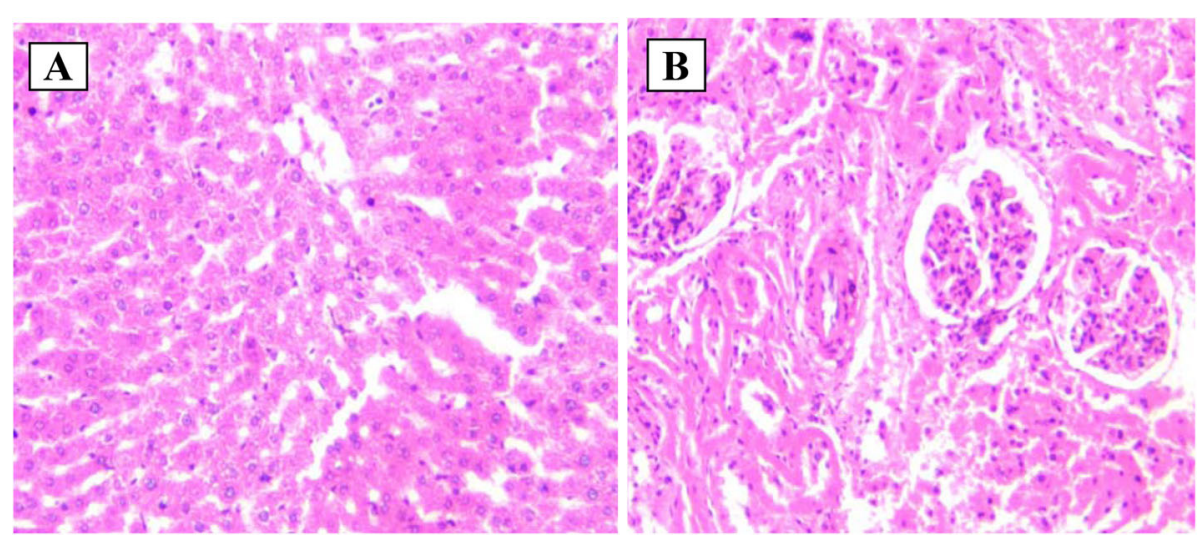

Fig. 1 Photomicrographs of liver and kidney of rat given distilled water only ( $\times 100, \mathrm{H}$ \& E stain); Morphology of liver tissue (a) showing normal hepatocytes, without any change in the tissue structural architecture, and kidney tissue (b) with normal glomeruli, Bowman's capsules and renal tubules

formed from creatine and phosphocreatine during muscle metabolism but excreted by glomerular filtration. Just like urea, the rate of excretion of creatinine is influenced by glomerular filtration rate (GFR), so any abnormality that decreases GFR will result in an increased serum creatinine [21, 22]. The significant increase in urea and creatinine levels after exposure of rats to cisplatin may be an indication of kidney impairments, due to the adverse effect of this drug. These findings suggest that there may be reduction in GFR of the animals and are in agreement with the findings of Kim et al. [1] and Rajakrishnan et al. [20] who reported that the alterations induced in kidneys by cisplatin were characterized by elevated levels of their injury markers. The significant reduction of urea and creatinine levels after treatment of rats with LLE and cisplatin may suggest that this plant extract has protective effect against cisplatin-induced kidney injuries in animals. The capacity of this plant extract to decrease urea and creatinine levels in rats may be attributed to its ability to protect the nephrons and increase GFR, as a result of its phytochemicals [21]. Previous studies have shown that certain plant extracts have protective effects against cisplatin-induced kidney injuries in animals by reduction of urea and creatinine levels $[1,20,22]$.

The liver plays a major role in controlling plasma levels of cholesterol, thus when there is drug-induced liver impairments, there will be elevated levels of serum total cholesterol (TC) and LDL-cholesterol [17]. The significant increase in serum levels of total cholesterol
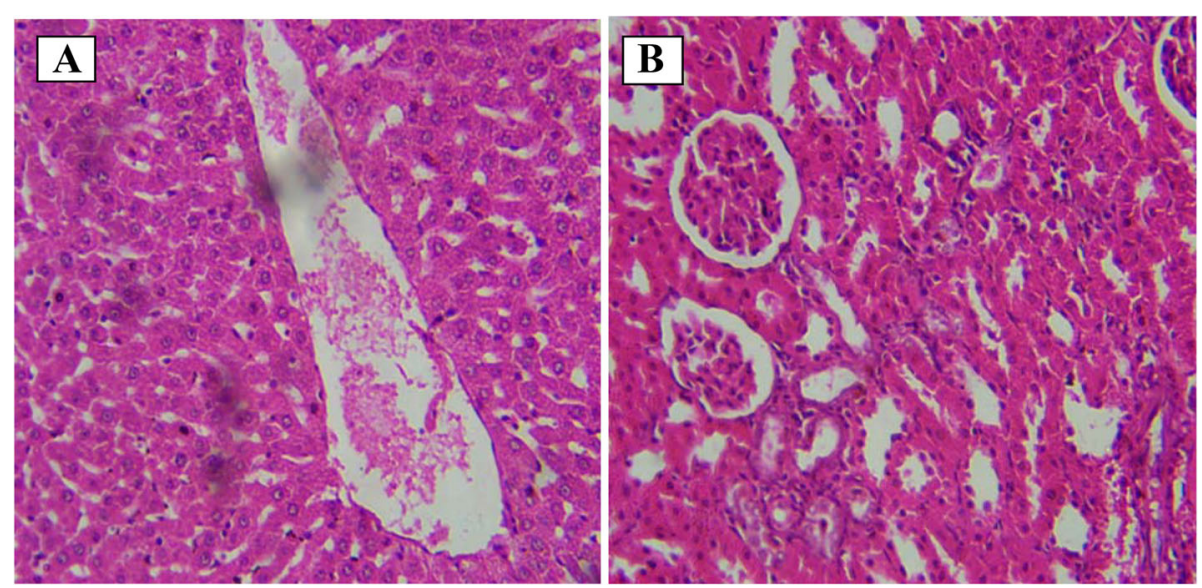

Fig. 2 Photomicrographs of liver and kidney of rat administered $5 \mathrm{mg} / \mathrm{kg}$ cisplatin ( $\times 100, \mathrm{H}$ \& E stain); Morphology of liver tissue (a) shows damaged hepatocytes, sinusoidal dilatation, hemorrhage in portal triad, vascular congestion, infiltration of portal triad and stroma of liver by inflammatory cells, and foci of coagulative necrosis. The kidney tissue (b) shows congestion of interstitial spaces with presence of casts, capsular dilation, shrunken and distorted glomeruli 


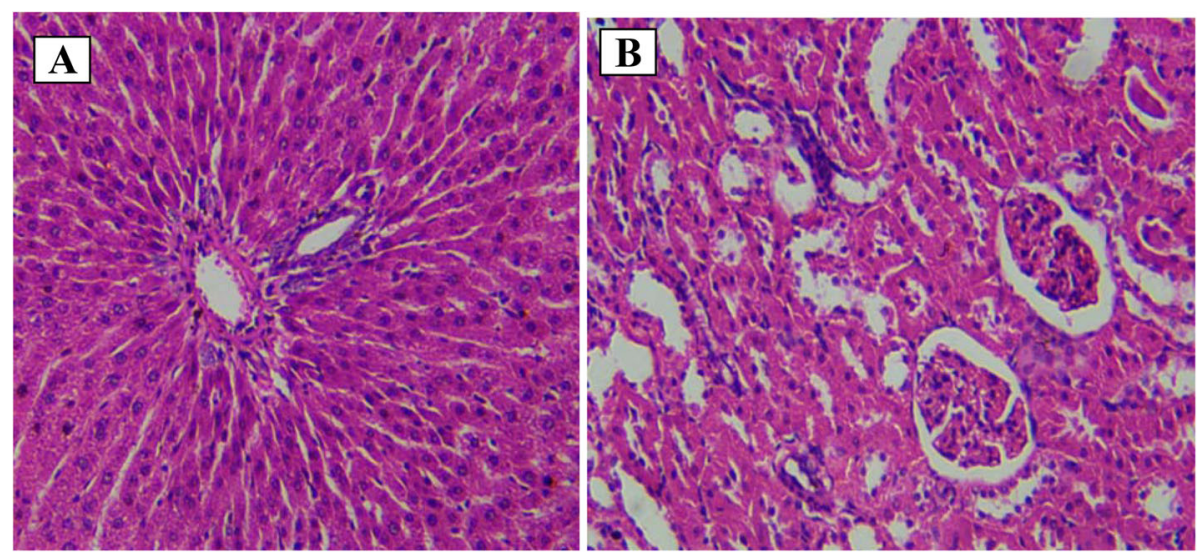

Fig. 3 Photomicrographs of liver and kidney of rat treated with $200 \mathrm{mg} / \mathrm{kg}$ L. lanceolata extract $(\times 100, \mathrm{H}$ \& E stain); Morphology of liver tissue (a) shows infiltration of hepatic cords by few inflammatory cells and small foci of coagulative necrosis. The kidney tissue (b) shows mild congestion of interstitial spaces, shrunken glomeruli and foci of interstitial nephritis

(TC), triglycerides (TG) and LDL-cholesterol after exposure of rats to cisplatin may be attributed to the adverse effect of this drug, leading to hepatocellular dysfunction and impaired lipid metabolism, which are in agreement with the findings of Akindele et al. [23]. It has been shown that elevated levels of TC, LDL-C and reduced level of HDL-C are risk factors for cardiovascular diseases [24]. The liver synthesizes triglycerides and incorporates them into very low density lipoprotein (VLDL) cholesterol for transport into peripheral tissues, thus when there is injury to the liver its capacity to synthesize VLDL-C is impaired, leading to elevated levels of TG [25].

Atherogenic dyslipidemia, characterized by high LDLC/HDL-C ratio and elevated TG, is associated with high cardiovascular risk [26]. Several clinical studies tried to find a better marker of atherogenic dyslipidemia, which can predict the risk of cardiovascular diseases (CVD) and useful for assessing response to treatment instead of the classical ratio $[26,27]$. It was then found that atherogenic index of plasma (AIP), as a marker of lipoprotein particle size, has predictive value for CVD risk than individual lipids and/or TC/HDL-C ratio [26, 28]. Thus, current scientific evidence indicates that AIP is a strong marker which can predict the risk of atherosclerosis and CVD [26]. The marked increase in the values of cardiac risk ratio (CRR), atherogenic coefficient (AC), and classical ratio (CR) but minimal increase in AIP of cisplatinexposed rats may indicate a moderate risk of atherosclerosis and CVD. These findings are in agreement with previous studies, which showed that dyslipidemic and atherogenic indices increase with increasing risk of CVD and vice versa [26-29].

The significant reduction in the levels of TC, LDL-C and TG by treatment of cisplatin-exposed rats with 200

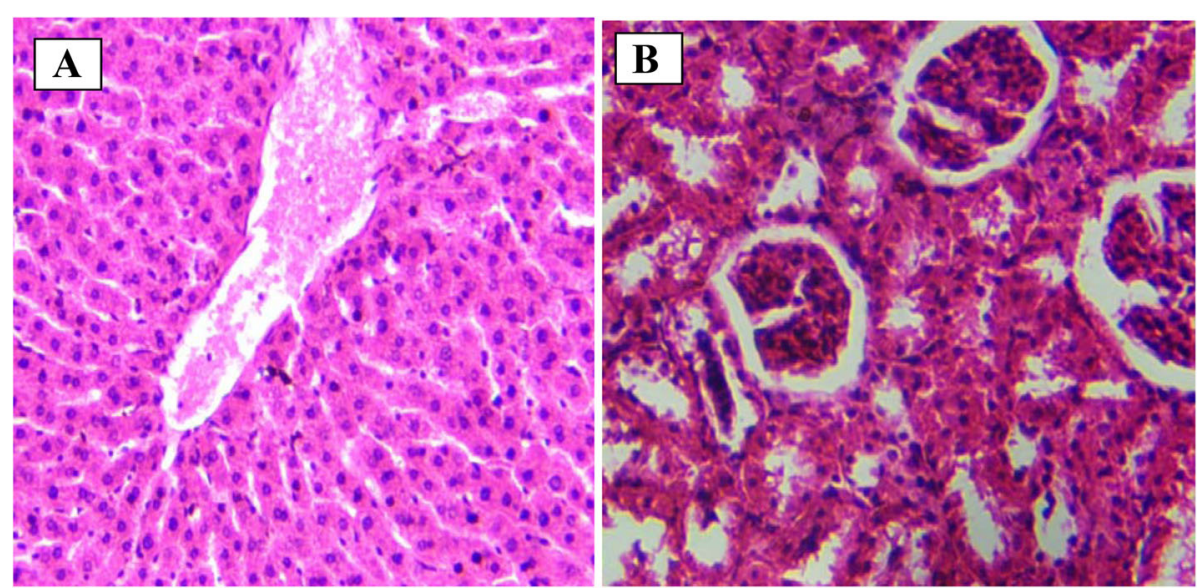

Fig. 4 Photomicrographs of liver and kidney of rat treated with $400 \mathrm{mg} / \mathrm{kg}$ L. lanceolata extract ( $\times 100, \mathrm{H}$ \& E stain); Morphology of liver tissue (a) shows infiltration of portal triad and hepatic cords by inflammatory cells, and vascular congestion. The kidney tissue (b) shows congestion of interstitial spaces, shrunken and distorted glomeruli 


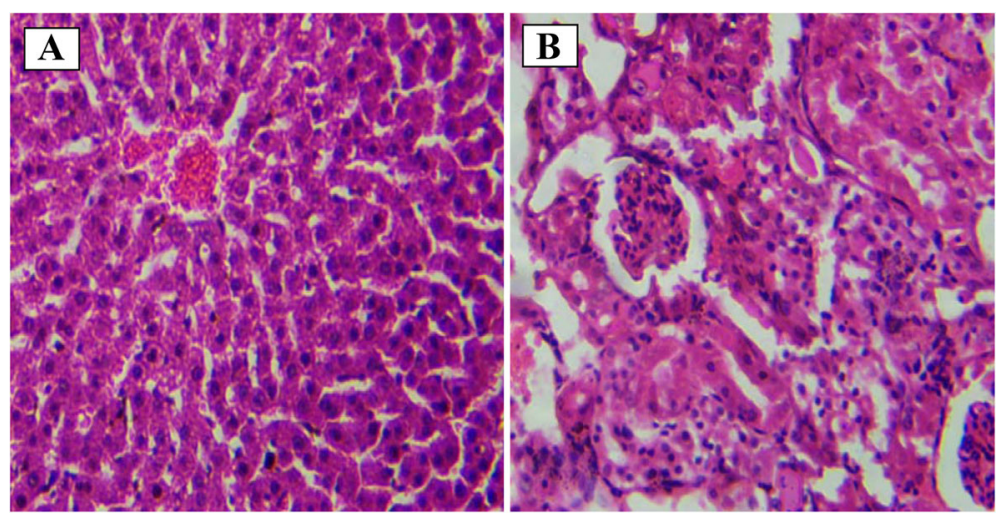

Fig. 5 Photomicrograph of liver and kidney of rat treated with $200 \mathrm{mg} / \mathrm{kg}$ L. lanceolata leaf extract and $5 \mathrm{mg} / \mathrm{kg}$ Cisplatin (× 100, H \& E stain); Morphology of liver tissue (a) shows hemorrhage in the portal triad, few inflammatory cells and pyknotic hepatocytes. The kidney tissue (b) shows shrunken glomeruli, congestion of interstitial spaces and infiltration by inflammatory cells, showing signs of mild interstitial nephritis

and $400 \mathrm{mg} / \mathrm{kg}$ LLE may indicate that the plant extract has protective effect against cisplatin-induced hyperlipidemia in rats, when given at the appropriate dose. These findings are in agreement with Akindele et al. [23] who found that plant extract has ameliorative effect on ethanol-induced elevated levels of cholesterol, TG and LDL-C in rats. The decrease in the values of CRR, AC, AIP and CR by treatment of cisplatinexposed rats with 200 and $400 \mathrm{mg} / \mathrm{kg}$ LLE may suggest a reduction in the risk of atherosclerosis and CVD, though the effect of low dose of extract was greater than the high dose. These findings are in agreement with Akindele et al. [23] who found that the values of CRR, AC and AIP were considerably reduced in ethanol-exposed rats by treatment with a medicinal plant extract.
The weight of animal's organ in relation to body weight is used to assess the level of tissue damage in animals [30]. It is widely accepted that alteration in the organ to body weight ratio of diseased animal is a useful indicator of tissue damage [31]. The significant reduction in the values of liver and kidney to body weight ratios after exposure of rats to cisplatin may indicate tissues degeneration and necrosis, attributed to the adverse effects of this drug. These findings are in agreement with Adebayo et al. [30] who found significant reduction in kidney to body weight ratio after exposure of rats to a toxin, and Olaniyan et al. [31] who reported that the alteration in organ to body weight ratio may be as a result of organ damage.

The significant increase in the values of liver and kidney to body weight ratios by treatment of cisplatin-
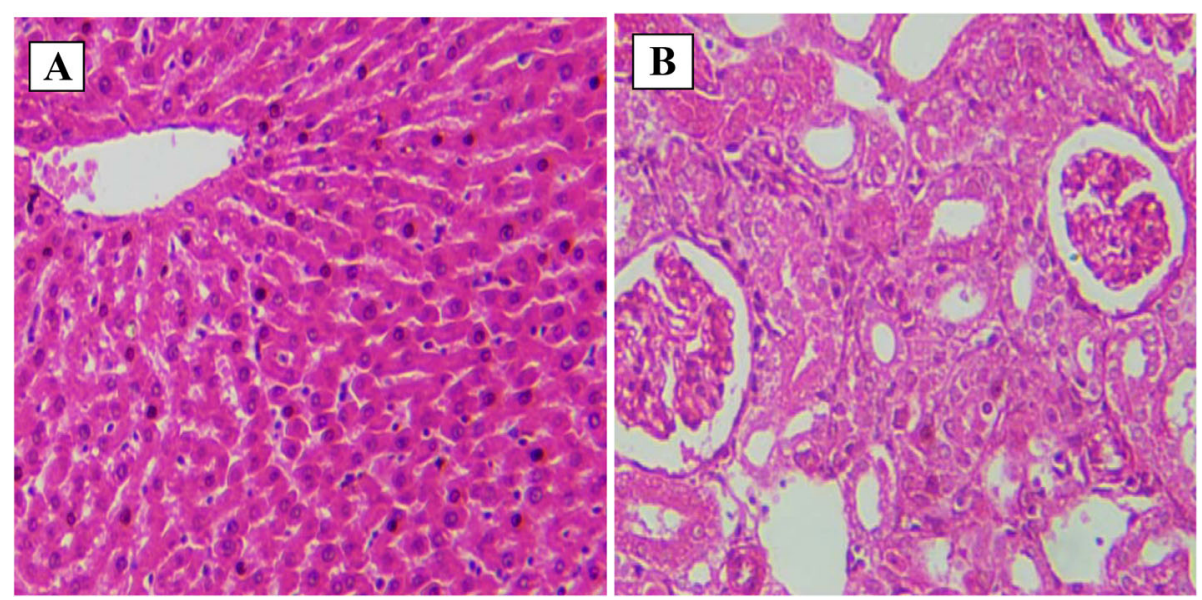

Fig. 6 Photomicrographs of liver and kidney of rat treated with $400 \mathrm{mg} / \mathrm{kg}$ L. lanceolata leaf extract and $5 \mathrm{mg} / \mathrm{kg}$ Cisplatin ( $\times 100, \mathrm{H}$ \& E stain). Morphology of liver tissue (a) shows mild congestion of the portal triad and infiltration of liver sinusoids by inflammatory cells and several pyknotic hepatocytes; The kidney tissue (b) shows shrunken and distorted glomeruli, mild hemorrhage and congestion in the interstitial spaces, showing signs of mild interstitial nephritis 
exposed rats with 200 and $400 \mathrm{mg} / \mathrm{kg}$ LLE, may suggest that this plant extract has protective effect against cisplatin-induced liver and kidney injuries in rats. These findings are in agreement with Adejor et al. [32] who found that the protective effect of plant extract prevented significant alteration in organ to body weight ratio of animals. Thus, the prevention of marked decrease in liver and kidney to body weight ratios in the current study, may suggest that LLE protected the liver and kidney of rats against cisplatin-induced injuries and necrosis.

The liver and kidney photomicrographs are commonly used to evaluate the extent of tissue damage, by the microscopic study of their structural architectures. Thus, histopathological findings in tissue sections of animals are commonly used to validate the biochemical findings of a study [33]. The histopathological changes observed in the photomicrographs of cisplatin-exposed rats agreed with the biochemical findings of this study. The presence of inflammatory cells and alterations in structural architectures of liver and kidney tissues of cisplatin-exposed rats are signs of pathology; indicating degenerative changes in hepatorenal tissues, by apoptotic and necrotic processes leading to cell death. These findings are in agreement with previous studies by Alqasoumi [19] and Al-Attar et al. [33] who found pathological changes in liver and kidney structures after exposure of animals to drugs; with features such as sinusoidal dilation, parenchyma inflammation and vascular congestion in liver, glomerular and tubular modifications in nephrons. Apoptotic and necrotic cell death are important in the pathogenesis of acute liver damage [34]. Cisplatin-induced tissue toxicity may generate reactive oxygen species (ROS), leading to induction of hepatocyte apoptosis, the activation of inflammatory cells and their infiltration of tissues, as well as tissue degenerative changes [35].

There are two major molecular pathways of caspasedependent apoptosis which are intrinsic and extrinsic [36], however the authors propose that the mechanism of cell death in this study may be by the intrinsic pathway. This pathway is activated in response to DNA damage, oxidative stress and other stress-inducing conditions. The multiple forms of stress converge on the mitochondria and cause mitochondrial outer membrane permeabilization (MOMP), which leads to dissipation of the mitochondrial membrane potential and cessation of ATP production, as well as release of a number of proteins that contribute to caspase activation [36]. In other words, intracellular stress induces the release of proteins (Bcl-2, Bak, Bax, tBid etc), which promote MOMP and release a number of proteins including cytochrome c (CYTC). The release of CYTC from the mitochondria leads to formation of apoptosome and activation of caspase 9 . Then caspases 8 and 9 activate downstream caspases like the caspase 3 resulting in apoptotic cell death. The apoptotic bodies once released are rapidly recognized by neighboring cells or professional phagocytes and are generally disposed without induction of inflammation [36, 37].

The marked decrease in number of inflammatory cells, reduced degenerative changes in kidney and liver tissues, by treatment of cisplatin-exposed rats with LLE, supported the biochemical findings that this plant extract may have protective effect against cisplatin-induced hepatic and renal injuries in rats. Previous studies have shown that plant extracts could prevent pathological changes in liver and kidney tissues of animals and sometimes may reverse pathological changes already induced by drugs that are toxic to animal tissues [19, 32, 33]. Though, no functional data was determined to investigate the mechanism of protection against drug-induced tissue damage, the protective effect of LLE in the current study may be attributed to the presence of phytochemicals which can scavenge ROS and free radicals generated by the drug, thereby preventing the oxidative damage of hepatorenal tissues in rats [23]. The changes in structural architectures of liver and kidney tissues of rats after treatment with LLE only, may suggest that this plant extract may have adverse effect on animal tissues, when given at higher doses and for long duration. These findings are in agreement with Etuk and Muhammad [11] who found signs of injuries in tissues of male rats after their treatment with similar plant extract.

\section{Conclusion}

The findings of this study have shown that aqueous extract of $L$. lanceolata leaf may have protective effect against cisplatin-induced hepatorenal injuries and dyslipidemia in rats, which may be attributed to the phytochemicals present in it. This gives credence to the use of this plant extract in traditional medicine for the treatment of diseases in humans. Further studies may be conducted in order to isolate and characterize the bioactive compounds responsible for the pharmacological activities of this plant extract, and to investigate its mechanism of protection against drug-induced tissue damage in animals.

\section{Abbreviations \\ AC: Atherogenic coefficient; AIP: Atherogenic index of plasma; B. wt.: Body weight; CIS: Cisplatin; CR: Classical ratio; CRR: Cardiac risk ratio: \\ CVD: Cardiovascular diseases; CYTC: Cytochrome C; GFR: Glomerular filtration rate; LLE: Lophira lanceolata leaf extract; LSD: Least significant difference; Mg/ kg: Milligramme per kilogramme; MOMP: Mitochondrial outer membrane permeabilization; NSAID: Non steroidal anti-inflammatory drug; ROS: Reactive oxygen species; SEM: Standard error of mean}

\section{Acknowledgements}

Not applicable.

Authors' contributions

AHA and RJO designed the experiment and supervised it. SPA and RJO conducted the biochemical, histological and statistical analyses, and 
interpreted the results. RJO wrote the first draft of this manuscript while AHA and SPA revised the manuscript for intellectual content. All authors read and approved the final draft of the manuscript.

\section{Authors' information}

Not applicable.

\section{Funding}

The research was fully funded by the authors.

\section{Availability of data and materials}

The data sets used and/or analyzed during the current study are available from the corresponding author on reasonable request.

\section{Ethics approval and consent to participate}

The protocols of this study were approved by the Animal Welfare and Ethics Committee of the College of Veterinary Medicine, Federal University of Agriculture, Makurdi, Nigeria.

\section{Consent for publication}

Not applicable.

\section{Competing interests}

The authors declare that they have no competing interests.

Received: 23 February 2019 Accepted: 29 December 2019

Published online: 06 January 2020

\section{References}

1. Kim ES, Lee JS, Akram M, Kim KA, Shin YJ, Yu JH, Bae ON. Protective activity of Dendropanax morbifera against cisplatin-induced acute kidney injury. Kid Blood Pres Res. 2015;40:1-12. https://doi.org/10.1159/000368466.

2. El-Hosseiny LS, Alqurashy NN, Sheweita SA. Oxidative stress alleviation by Sage essential oil in co-amoxiclav induced hepatotoxicity in rats. Int J Biomed Sci. 2016;12(2):71-8.

3. Kadir AF, Kassim MN, Abdullah AM, Yehye AW. Effect of oral administration of ethanolic extract of Vitex negundo on thioacetamide-induced nephrotoxicity in rats. BMC Complement Alt Med. 2013;13:294. https://doi. org/10.1186/1472-6882-13-294

4. Couser WG, Remuzzi G, Mendis S, Tonelli M. The contribution of chronic kidney disease to the global burden of major noncommunicable diseases. Kidney Int. 2011;80:1258-70. https://doi.org/10.1038/ki.2011.

5. Naughton CA. Drug-induced nephrotoxicity. Am Fam Physician. 2008;78(6): 743-50.

6. Cummings KC. Lipid and cardiac risk profiles. Clin Chem. 2003;47:407-9.

7. Lirdi LC, Stupp T, Sasso-Cerri E, Miraglia SM. Amifostine protective effect on cisplatin-treated rat testis. The Anat Rec. 2008;291:797-808.

8. Yıldırım S, Karadeniz A, Karakoç A, Yıldırım A, Kalkan Y, Simşek N. Effects of royal jelly on liver paraoxonase activity in rats treated with cisplatin. Turk J Med Sci. 2012:42:367-75.

9. Burkill HM. Useful plants of west tropical Africa. $2^{\text {nd }}$ ed. Vol. 1: Families A - D Kew: Royal Botanic Gardens; 1985.

10. Etuk EU, Muhammad AA, lgbokwe V, Okolo RU. Sexual stimulatory effects of aqueous stem bark extract of Lophira lanceolata in male Sprague Dawley rats. J Clin Med Res. 2009;1(2):18-21.

11. Etuk EU, Muhammad AA. Safety evaluations of aqueous stem bark extract of Lophira lanceolata in Sprague Dawley rats. Int J Res Pharm Sci. 2010;1(1):2833.

12. Collins AO, Peter AA, Chukwuemeka SN, Theophine CO, Florence NM, Ifeoma AN, Nelson O, Obinna O. Antiplasmodial and antioxidant activities of methanol extract of the fresh leaf of Lophira lanceolata (Ochnaceae). Afr J Biotech. 2014;13(16):1731-8.

13. Audu S, Mohammed I, Kaita H. Phytochemical screening of the leaves of Lophira lanceolata (Ochnaceae). Life Sci J. 2007;4(4):75-9.

14. Ikewuchi CC. Hypocholesterolemic effect of an aqueous extract of the leaves of Sansevieria senegambica baker on plasma lipid profile and atherogenic indices of rats fed egg yolk supplemented diet. Excli J. 2012;11: 318-27.

15. Acay A, Ulu MS, Ahseh A, Ozkececi G, Demir K, Ozuguz U, Yuksel S, Acarturk $G$. Atherogenic index as a predictor of atherosclerosis in subjects with familial Mediterranean fever. Medicina. 2014;50:329-33.
16. Choji TPP, Ngokere AA, Ogenyi SI, Kumbish PR. Histoarchitectural evaluation of conventional versus two rapid microwave processing techniques. $\mathrm{Br}$ Biotech J. 2015;8(3):1-19.

17. Atawodi SE, Yakubu OE, Liman ML, lliemene DU. Effect of methanolic extract of Tetrapleura tetraptera (Schum and Thonn) Taub leaves on hyperglycemia and indices of diabetic complications in alloxan-induced diabetic rats. Asian Pac J Trop Biomed. 2014;4(4):272-8.

18. Sasidharan S, Aravindran S, Latha LY, Vijenthi R, Saravanan D, Amutha S. In vitro antioxidant activity and hepatoprotective effect of Lentinula edodes against paracetamol-induced hepatotoxicity. Molecules. 2010;15(6):4478-89.

19. Alqasoumi SI. Evaluation of the hepatoprotective and nephroprotective activities of Scrophularia hypericifolia growing in Saudi Arabia. Saudi Pharm J. 2014:22:258-63.

20. Rajakrishnan R, Lekshmi R, Benil PB, Thomas J, Alfarhan AH, Rakesh V, Khalaf S. Phytochemical evaluation of roots of Plumbago zeylanica $\mathrm{L}$. and assessment of its potential as a nephroprotective agent. Saudi J Biol Sci. 2017;24:760-6

21. Konda RV, Arunachalam R, Eerike M, Ramesh RK, Radhakrishnan KA, Raghuraman PL, et al. Nephroprotective effect of ethanolic extract of Azima tetracantha root in glycerol induced acute renal failure in Wistar albino rats. J Tradit Complement Med. 2016:6:347-54

22. el SM E-S, Abdel-Raouf OM, Fawzy HM, Manie MF. Comparative study of the possible protective effects of cinnamic acid and cinnamaldehyde on cisplatin-induced nephrotoxicity in rats. J Biochem Mol Toxicol. 2013;27(12): 508-14. https://doi.org/10.1002/jbt.2 1515.

23. Akindele JA, lyamu AE, Dutt P, Satti KN, Adeyemi OO. Ameliorative effect of hydroethanolic leaf extract of Byrsocarpus coccineus in alcohol- and sucroseinduced hypertension in rats. J Tradit Complement Med. 2014;4(3):177-88. https://doi.org/10.4103/2225-4110.129562.

24. Parinita K. Study of serum lipid profile in individuals residing in and around Nalgonda. Int J Pharm Bio Sci. 2012;2:110-6

25. Manninen V, Tenkanen $L$, Koshinen $P$, Huttunen JK, Mänttäri M, Heinonen $O P$, et al. Joint effects of serum triglyceride and LDL cholesterol and HDL cholesterol concentrations on coronary heart disease risk in the Helsinki Heart Study: implications for treatment. Circulation. 2002:85:37-45.

26. Niroumand S, Khajedaluee M, Khadem-Rezaiyan M, Abrishami M, Juya M, Khodaee G, Dadgarmoghaddam M. Atherogenic index of plasma (AIP): A marker of cardiovascular disease. Med J Islam Repub Iran. 2015;29:240.

27. Mudhaffar SK. Atherogenic index of plasma (AIP) as a parameter in predicting cardiovascular risk in males compared to the conventional dyslipidemic indices (cholesterol ratios). Karbala J Med. 2013;6(1):1506-13.

28. Dobiasova M, Frohlich J. The plasma parameter log (TG/HDL-C) as an atherogenic index: correlation with lipoprotein particle size and esterification rate in apo B-lipoprotein-depleted plasma (FERHDL). Clin Biochem. 2001;34:583-8

29. Nwagha UI, Ikekpeazu EJ, Ejezie FE, Neboh EE, Maduka IC. Atherogenic index of plasma as useful predictor of cardiovascular risk among postmenopausal womwn in Enugu, Nigeria. Afr Health Sci. 2010;10(3):248-52.

30. Adebayo OJ, Yakubu TM, Egwim CE, Owoyele BV, Enaibe UB. Effect of ethanolic extract of Khaya senegalensis on some biochemical parameters of rat kidney. J Ethnopharmacol. 2003;88:69-72.

31. Olaniyan MJ, Muhammed LH, Makun AH, Busari BM, Abdullahi SA. Acute and subacute toxicity studies of aqueous and methanol extracts of Nelsonia campestris in rats. J Acute Dis. 2016:5(1):62-70.

32. Adejor EB, Ameh DA, James BD, Owolabi OA, Ndidi US. Effects of Garcinia kola biflavonoid fractions on serum lipid profile and kidney function parameters in hyperlipidemic rats. Clin Phytosci. 2003;2:19. https://doi.org/ 10.1186/s40816-016-0033-4.

33. Al-Attar MA, Alrobai AA, Almalki AD. Protective effect of olive juniper leaves extracts on nephrotoxicity induced by thioacetamide in male mice. Saudi J Biol Sci. 2015;24(1):15-22. https://doi.org/10.1016/j.sjbs. 2015.08.013.

34. Bechmann LP, Jochum C, Kocabayoglu P, Sowa JP, Kassalik M, Gieseler RK, Saner F, Paul A, Trautwein C, Gerken G, Canbay A. Cytokeratin 18-based modification of the MELD score improves prediction of spontaneous survival after acute liver injury. J Hepatol. 2010;53(4):639-47. https://doi.org/ 10.1016/j.jhep.2010.04.029.

35. Bechmann LP, Hannivoort RA, Gerken G, Hotamisligil GS, Trauner M, Canbay A. The interaction of hepatic lipid and glucose metabolism in liver diseases. J Hepatol. 2012;56:952-64. 
36. Favaloro B, Allocati N, Graziano V, Di Illio C, De Laurenzi V. Role of apoptosis in disease. Aging. 2012;4(5):330-49.

37. Wickman G, Julian L, Olson MF. How apoptotic cells aid in the removal of their own cold dead bodies. Cell Death Differ. 2012;19:735-42.

\section{Publisher's Note}

Springer Nature remains neutral with regard to jurisdictional claims in published maps and institutional affiliations.

Submit your manuscript to a SpringerOpen ${ }^{\mathcal{O}}$ journal and benefit from:

- Convenient online submission

- Rigorous peer review

- Open access: articles freely available online

- High visibility within the field

- Retaining the copyright to your article

Submit your next manuscript at $\boldsymbol{\wedge}$ springeropen.com 